\title{
Comportamento Termomecânico de Compósitos Ativos Preparados com Nanocompósitos Epóxi/Argila Organofílica e Fios de Liga Ni-Ti com Memória de Forma
}

\author{
Artur S. C. Leal \\ Programa de Pós-Graduação em Ciência e Engenharia de Materiais, UFCG
}

Suédina M. L. Silva

Unidade Acadêmica de Engenharia de Materiais, UFCG

Carlos J. de Araújo

Unidade Acadêmica de Engenharia Mecânica, UFCG

\begin{abstract}
Resumo: Neste trabalho, nanocompósitos epóxi/argila organofílica foram selecionados como matriz por apresentarem valores de temperatura de transição vítrea $\left(\mathrm{T}_{\mathrm{g}}\right)$ e estabilidade térmica suficientemente alta para que fios de uma liga com memória de forma (LMF) possam ser incorporados. Para tanto, quatro frações volumétricas de fios LMF de Ni-Ti (1,55, 2,56, 3,57 e 4,54\%) foram embebidas na matriz epoxídica diglicidil éter do bisfenol-A (DGEBA), reticulada com a amina aromática 4,4'-diamino difenil sulfona (DDS) contendo 1 pcr da argila bentonita purificada organofiliada (APOC). A formação do nanocompósito foi confirmada por análise de difração de raio X, enquanto a transformação de fase dos fios de Ni-Ti foi determinada por análise dinâmico-mecânica (DMA). As amostras dos compósitos ativos preparados a partir da matriz de nanocompósito e fios de Ni-Ti foram caracterizadas principalmente por DMA. De acordo com os resultados obtidos foi constatada uma recuperação do módulo de armazenamento do compósito ativo durante o aquecimento na faixa de transformação de fase dos fios de Ni-Ti quando a fração volumétrica foi mantida em torno de 3,5\%.
\end{abstract}

Palavras-chave: Nanocompósito epóxi, ligas com memória de forma, compósitos ativos.

\section{Thermomechanical Behavior of Active Composites Prepared with Epoxy/Organoclay Nanocomposites and Ni-Ti Shape Memory Alloy Wires}

\begin{abstract}
In this work, epoxy/organoclay nanocomposites were selected as matrix for presenting high enough glass transition temperature $\left(\mathrm{T}_{\mathrm{g}}\right)$ and thermal stability values in order to be incorporated in shape memory alloys (SMA). Four volume fractions of SMA wires containing Ni-Ti $(1.55,2.56,3.57$ and $4.54 \%)$ were embedded in diglycidyl ether of bisphenol A (DGEBA), cured with the aromatic amine 4,4'-diamino diphenyl sulfone (DDS) and containing $1 \mathrm{phr}$ of purified organobentonite (APOC). The formation of nanocomposite was confirmed by $\mathrm{X}$ ray diffraction analysis, while the phase transformation of Ni-Ti wires was determined by dynamic mechanical analysis (DMA). Samples of the active composites prepared from nanocomposite matrix and Ni-Ti wires were mainly characterized by DMA. A recovery of the storage modulus of the active composite was observed during heating in the range of phase transformation of $\mathrm{Ni}$-Ti wires when the volume fraction was maintained at around $3.5 \%$.
\end{abstract}

Keywords: Epoxy nanocomposite, shape memory alloys, active composites.

\section{Introdução}

Compósitos ativos, muitas vezes denominados na literatura de compósitos inteligentes, podem ser obtidos com a incorporação de fios ou partículas de liga com memória de forma (LMF) a uma matriz polimérica de interesse. A obtenção dessa classe de material permite um conjunto de novas oportunidades e de inovação tecnológica, uma vez que a necessidade de materiais mais resistentes, mais leves, polivalentes e, sobretudo com algum grau de funcionalidade controlada por parâmetros ambientais como campos de temperatura e magnetismo, pode se tornar uma realidade industrial em um futuro próximo ${ }^{[1]}$.

As LMF vêm sendo usadas para diversas aplicações como atuadores termomecânicos em dispositivos para uma variedade de segmentos, como biomedicina, petróleo e gás, indústria aeroespacial, automotivo, mecatrônica e eletroeletrônica ${ }^{[2]}$. Vários estudos reportados na literatura estão sendo direcionados ao uso de LMF embebidas em sistemas epoxídicos ${ }^{[1-9]}$. Esse desenvolvimento tecnológico vem ocorrendo devido à necessidade de utilização de materiais com propriedades especiais, não encontradas em um único material, mas que podem ser obtidos pela combinação de diversos outros, originando propriedades singulares.

Os materiais metálicos que apresentam o fenômeno conhecido por efeito memória de forma (EMF) são considerados intrinsecamente como atuadores termomecânicos em virtude da capacidade que apresentam de produzir um deslocamento importante, associado a uma recuperação de deformação "aparentemente plástica", quando submetidos a uma variação de temperatura ${ }^{[9]}$. Este deslocamento pode corresponder a uma deformação introduzida, e recuperável por simples aquecimento, de até $8 \%$. Essa reversibilidade da forma responsável pela produção de um deslocamento, muitas vezes contrário à dilatação térmica dos metais convencionais, pode ser acompanhada de um trabalho mecânico externo caso o material atuador esteja submetido a um carregamento mecânico durante seu aquecimento. Assim, um fio com EMF pode levantar um peso quando aquecido.

Autor para correspondência: Suédina Maria de L. Silva, Unidade Acadêmica de Engenharia de Materiais, Universidade Federal de Campina Grande - UFCG, Rua Aprígio Veloso, 882, Bairro Universitário, CEP 58429-140, Campina Grande, PB, Brasil, e-mail: suedina@dema.ufcg.edu.br 


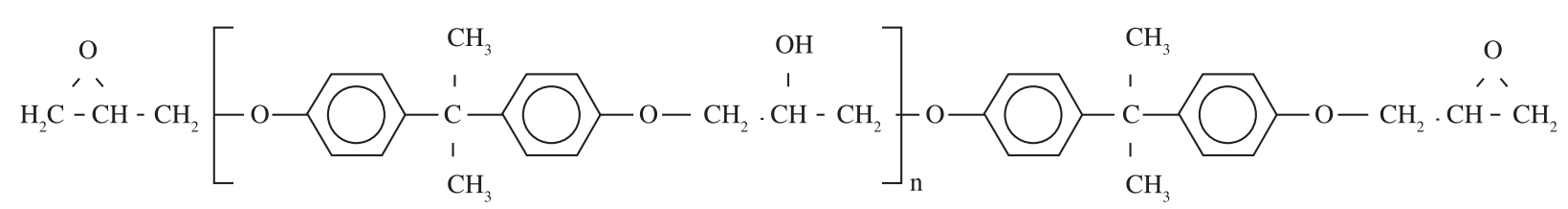

(a)

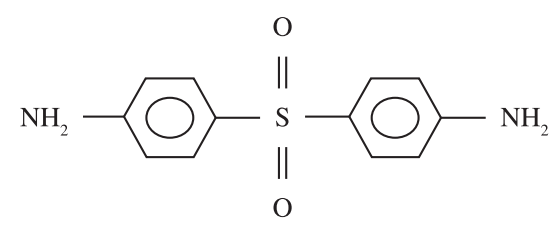

(b)

Figura 1. Estrutura química da resina epóxi (a) resina bifuncional diglicidil éter do bisfenol-A (DGEBA) e do agente de cura (endurecedor) (b) amina aromática 4,4'-diamino difenil sulfona (DDS).

Alternativamente, se a deformação recuperável por EMF é restringida de alguma forma quando o material é aquecido, uma força considerável pode ser gerada. Vale ressaltar que qualquer um dos modos de transferência de calor (condução, convecção e radiação) pode ser usado para acionar o elemento à memória de forma $^{[6]}$.

Há aproximadamente uma década, o comportamento estrutural de compósitos com fios de LMF embebidos vem despertando o interesse da comunidade científica. Nesse contexto, Bidaux et al. ${ }^{[8]}$ avaliaram a influência da transformação martensítica de uma LMF nas propriedades viscoeláticas de uma matriz epóxi, comparando o comportamento dinâmico-mecânico dos compósitos com fios de Ni-Ti incorporados. Os resultados foram apresentados em função da interação LMF/matriz polimérica, e embora a fração volumétrica utilizada tenha sido relativamente baixa $(2,4 \%)$, houve um aumento em torno de $20 \%$ no módulo de elasticidade do compósito epóxi/ LMF com o aquecimento entre 20 e $80^{\circ} \mathrm{C}$.

Informações a respeito do comportamento microestrutural, termomecânico e funcional de fios de LMF tem sido reportadas na literatura ${ }^{[7,9,10]}$, mas pouco se sabe sobre o seu comportamento quando embebidos em matriz de nanocompósito epóxi/argila organofílica. Portanto, o objetivo deste trabalho é investigar o efeito da fração volumétrica de fios de uma LMF de Ni-Ti no comportamento termomecânico de um nanocompósito epóxi/argila organofílica.

\section{Experimental}

\section{Materiais}

A resina selecionada para a realização deste estudo foi a epóxi diglicidil éter do bisfenol-A (DGEBA), de nome comercial SQ 2001, fornecida pela Silaex ${ }^{\circledR}$ Química Ltda. Esta resina tem uma massa de epóxi correspondente a $18-192 \mathrm{~g} \mathrm{eq}^{-1}$ e viscosidade $11000-14000 \mathrm{cP}$ a temperatura de $25{ }^{\circ} \mathrm{C}$, conforme informações do fornecedor ${ }^{[11]}$. Esse sistema foi reticulado com o agente de cura amina aromática 4,4'-diamino difenil sulfona (DDS), de nome comercial AradurTM 976, fornecido pela empresa HUNTSMAN. As estruturas químicas da resina epóxi e do agente de cura (endurecedor) estão apresentadas na Figura 1.

A argila usada para a obtenção do nanocompósito foi a argila organofílica APOC, fornecida pelo Laboratório de Nanocompósitos Poliméricos-NanoPol da Unidade Acadêmica de Engenharia de Materiais da Universidade Federal de Campina Grande-UFCG. Esta argila foi modificada com o surfactante brometo de cetil trimetil

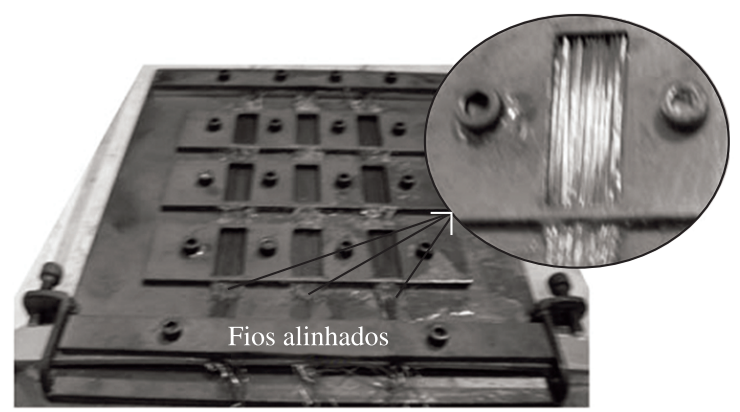

Figura 2. Molde metálico confeccionado para preparação dos compósitos ativos, destacando os fios de Ni-Ti alinhados.

amônio $\left(\mathrm{C}_{16} \mathrm{H}_{33} \mathrm{~N}+\left(\mathrm{CH}_{3}\right)_{3} \mathrm{Br}-\right)$, de nome comercial Cetremide, e apresenta uma distância interplanar basal $\left(\mathrm{d}_{001}\right)$ de $1,85 \mathrm{~nm}^{[12]}$.

Os fios da LMF Ni-Ti foram fornecidos pela empresa alemã Memory-Metalle GmbH (Alemanha), no estado bruto de fabricação, com diâmetro de 0,29 mm. Esta LMF é denominada pela empresa de liga $\mathrm{H}$, com composição química 49,8 Ni e 50,2 Ti (\%at). Esses fios foram recozidos por 20 minutos a $450{ }^{\circ} \mathrm{C}$ em forno elétrico, seguido de resfriamento ao ar a temperatura ambiente. Este tratamento térmico libera a transformação martensítica reversível responsável pelo aparecimento do fenômeno de memória de forma nos fios Ni-Ti, pois há uma estabilização da martensita devido ao encruamento oriundo do processo de fabricação ${ }^{[6]}$.

\section{Preparação das amostras}

Inicialmente os fios LMF de $\mathrm{Ni}-\mathrm{Ti}$, tratados termicamente e lixados visando obter uma superfície irregular, foram alinhados em um molde metálico com cavidades retangulares de $30,0 \times 12,7 \times 3,2 \mathrm{~mm}$, correspondentes ao formato de corpos de prova para as análises dinâmico-mecânicas (DMA). Esse molde foi confeccionado especialmente para preparação dos compósitos ativos, conforme mostra a fotografia da Figura 2. Posteriormente, o nanocompósito epóxi/argila organofílica, preparado conforme a seguinte metodologia:

A mistura DGEBA/argila organofílica foi preparada na presença do agente de cura DDS. Para tanto, $40 \mathrm{~g}$ de resina DGEBA, 44 pcr do endurecedor DDS e 1 pcr de argila APOC foram previamente aquecidos em estufa a $110^{\circ} \mathrm{C}$ por 20 minutos, em seguida a argila foi adicionada a resina epóxi DGEBA e agitada mecanicamente ( 200 rpm) a $90{ }^{\circ} \mathrm{C}$ por 1 hora. Após este período o endurecedor foi adicionado e misturado durante 15 minutos a temperatura ambiente, 
em seguida vertido no molde metálico contendo os fios de LMF $\mathrm{Ni}$-Ti mecanicamente alinhados. O tratamento de pós-cura foi conduzido a $200{ }^{\circ} \mathrm{C}$ por 2 horas ${ }^{[13]}$.

$\mathrm{O}$ tratamento de cura foi realizado empregando o procedimento que resultou na maior estabilidade térmica e na maior temperatura de transição vítrea $\left(\mathrm{T}_{\mathrm{g}}\right)$, conforme estabelecido previamente ${ }^{[13]}$. Os compósitos ativos contendo 1,55, 2,56, 3,57 e 4,54\% em volume de fios de Ni-Ti foram codificados como EPX_DDS.APOC 1.55, EPX_DDS.APOC 2.56, EPX_DDS.APOC 3.57 e EPX_DDS. APOC 4.54, respectivamente.

\section{Caracterização}

Para avaliar a intercalação/esfoliação da argila organofílica APOC, na matriz epóxi, análises de difração de raio X (DRX) foram conduzidas a temperatura ambiente, em um equipamento Shimadzu XDR-6000 a $40 \mathrm{kV}$ e $30 \mathrm{~mA}$ e com um comprimento de onda $\lambda \mathrm{CuK} \alpha$ $(\lambda=1,5418 \AA$ ). As amostras foram examinadas em um intervalo de $2 \theta$ entre 2,0 e $12,0^{\circ}$ a uma taxa de $1{ }^{\circ} \mathrm{C} / \mathrm{min}$. Padrões de difração de raio $\mathrm{X}$ foram obtidos para determinar o espaçamento interplanar basal $\left(\mathrm{d}_{001}\right)$ da argila organofílica APOC não incorporada e incorporada à matriz polimérica (resina epóxi) por meio da lei de Bragg.

Testes de análise térmica dinâmico-mecânica (DMA) foram realizados nas amostras obtidas com o molde da Figura 2, utilizando um equipamento DMA, modelo Q800, da TA Instruments. As amostras foram submetidas à solicitação mecânica em modo de flexão simples (single cantilever) e as condições do ensaio foram: frequência de $1 \mathrm{~Hz}$, amplitude de oscilação de $15 \mu \mathrm{m}$, taxa de aquecimento de $2{ }^{\circ} \mathrm{C} / \mathrm{min}$ e intervalo de temperatura de 30 a $160{ }^{\circ} \mathrm{C}$.

A estrutura macromecânica do compósito ativo foi observada utilizando um microscópio eletrônico de varredura (MEV), da marca HITACHI, modelo TM 1000. As amostras foram cortadas usando uma cortadora metalográfica de precisão, e a superfície observada diretamente utilizando o equipamento.

\section{Resultados e Discussão}

\section{Morfologia dos sistemas epoxídicos/argila organofílica}

Os nanocompósitos foram obtidos quando 1 per de argila APOC foi adicionado a resina epóxi. A Figura 3 mostra o difratograma da argila APOC e do sistema epoxídico pós-curado contendo 1 pcr de argila organofílica (EPX_DDS.APOC). A argila apresentou o pico (001) em $2 \theta=4,75^{\circ}$ que corresponde a um espaçamento basal $\left(\mathrm{d}_{001}\right)$ de $1,85 \mathrm{~nm}$. Contudo, nenhum pico de difração característico aparece na faixa de $2 \theta$ de 2 a $12^{\circ}$ para o sistema EPX_DDS.APOC, indicando que os valores de $\mathrm{d}_{001}$ são maiores do que $4,4 \mathrm{~nm}$ e que um nanocompósito com estrutura predominantemente esfoliada foi obtido. Estes resultados estão de acordo com a literatura ${ }^{[14]}$, onde tem sido mostrado que existe uma correlação direta entre os dados de DRX e os dados de microscopia eletrônica de transmissão (MET), ou seja, ausência de pico (001) no difratograma tem correspondido a obtenção de nanocompósito com estrutura esfoliada.

Nos estudos realizados por Gupta et al. ${ }^{[14]}$ nanocompósitos epóxi/argila organofílica com estrutura esfoliada foram obtidos quando $1 \%$ em volume de Cloisite 30B foi adicionada a resina epóxi DGEBA. Resultados semelhantes foram obtidos por Wang et al. ${ }^{[15]}$.

\section{Comportamento termomecânico dos sistemas epoxídicos/argila organofilica}

A incorporação de 1 pcr de argila organofílica APOC ao sistema epoxídico EPX_DDS resultou em um aumento, de aproximadamente $9{ }^{\circ} \mathrm{C}$, da temperatura de transição vítrea $\left(\mathrm{T}_{\mathrm{g}}\right)$ deste sistema, conforme verifica-se na Figura 4. O efeito da adição de argila organofílica na temperatura $\mathrm{T}_{\mathrm{g}}$ de sistemas epoxídicos tem sido amplamente estudado por muitos pesquisadores. Alguns deles reportaram um aumento nos valores de $\mathrm{T}_{\mathrm{g}}^{[17,18]}$, enquanto outros observaram uma ligeira diminuição ou nenhuma alteração nos valores $^{[14,19]}$. O aumento da $\mathrm{T}_{\mathrm{g}}$ tem sido atribuído ao retardamento do movimento molecular devido a interação das cadeias poliméricas com a alta área superficial da argila dispersa na matriz e a redução tem sido atribuída a fatores como efeito plastificante dos íons orgânicos empregados na organofilização da argila, ruptura da estrutura reticulada ou aprisionamento de monômeros residuais nas galerias da argila ${ }^{[18]}$. Neste estudo foi observado um aumento nos valores de $\mathrm{T}_{\mathrm{g}}$ dos sistemas epoxídicos quando argila organofílica APOC foi incorporada.

A Figura 4 também mostra que a estabilidade térmica do sistema epoxídico foi alterada quando 1 pcr de argila organofílica APOC foi incorporado ao mesmo. O nanocompósito (EPX_DDS.APOC) tornou-se mais estável termicamente do que o sistema epoxídico puro (EPX_DDS). Na temperatura de $120^{\circ} \mathrm{C}$, por exemplo, o módulo de armazenamento foi de $1330 \mathrm{MPa}$ para o sistema EPX_DDS. APOC e de $580 \mathrm{MPa}$ para o sistema EPX_DDS. Existe uma relação deste comportamento com a morfologia do nanocompósito. De acordo com os dados de DRX (Figura 3) a morfologia apresentada pelo sistema epoxídico EPX_DDS.APOC foi predominantemente esfoliada devido, possivelmente, as maiores interações entre os grupos hidroxila da argila organofílica e o grupo sulfonado do agente de cura DDS. Isto pode ter contribuído para a formação de fortes forças de interação entre a resina epóxi e a argila organofílica já que as cadeias poliméricas de epóxi são presas na superfície da argila através de ligações hidrogênio, devido as interações entre os grupos hidroxila da argila organofílica e os grupos éter da resina epóxi, conforme ilustra a Figura 5. Isto restringe a mobilidade das cadeias poliméricas, pois estas fortes ligações hidrogênio atuam como reticulações físicas e diminuem o volume médio livre da matriz polimérica, o que pode ter resultado nos maiores valores de $\mathrm{T}_{\mathrm{g}}$ e de módulo de armazenamento (E') observados ${ }^{[13,19-21]}$.

\section{Comportamento termomecânico dos compósitos ativos}

Uma vez que o nanocompósito epóxi/argila organofília (EPX_ DDS.APOC) apresentou maior $\mathrm{T}_{g}$ e maior estabilidade térmica do que a resina pura (EPX_DDS), o mesmo foi empregado como matriz polimérica na preparação dos compósitos ativos (matriz polimérica/ fios da LMF Ni-Ti). Isto porque, na preparação de compósitos ativos

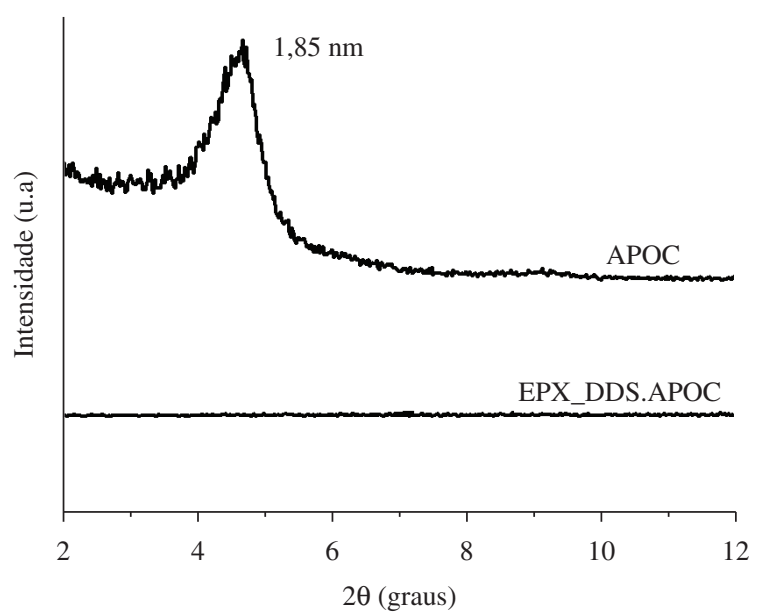

Figura 3. Difratograma da argila APOC e do sistema epoxídico pós-curado contendo 1 per de argila organofílica APOC. 


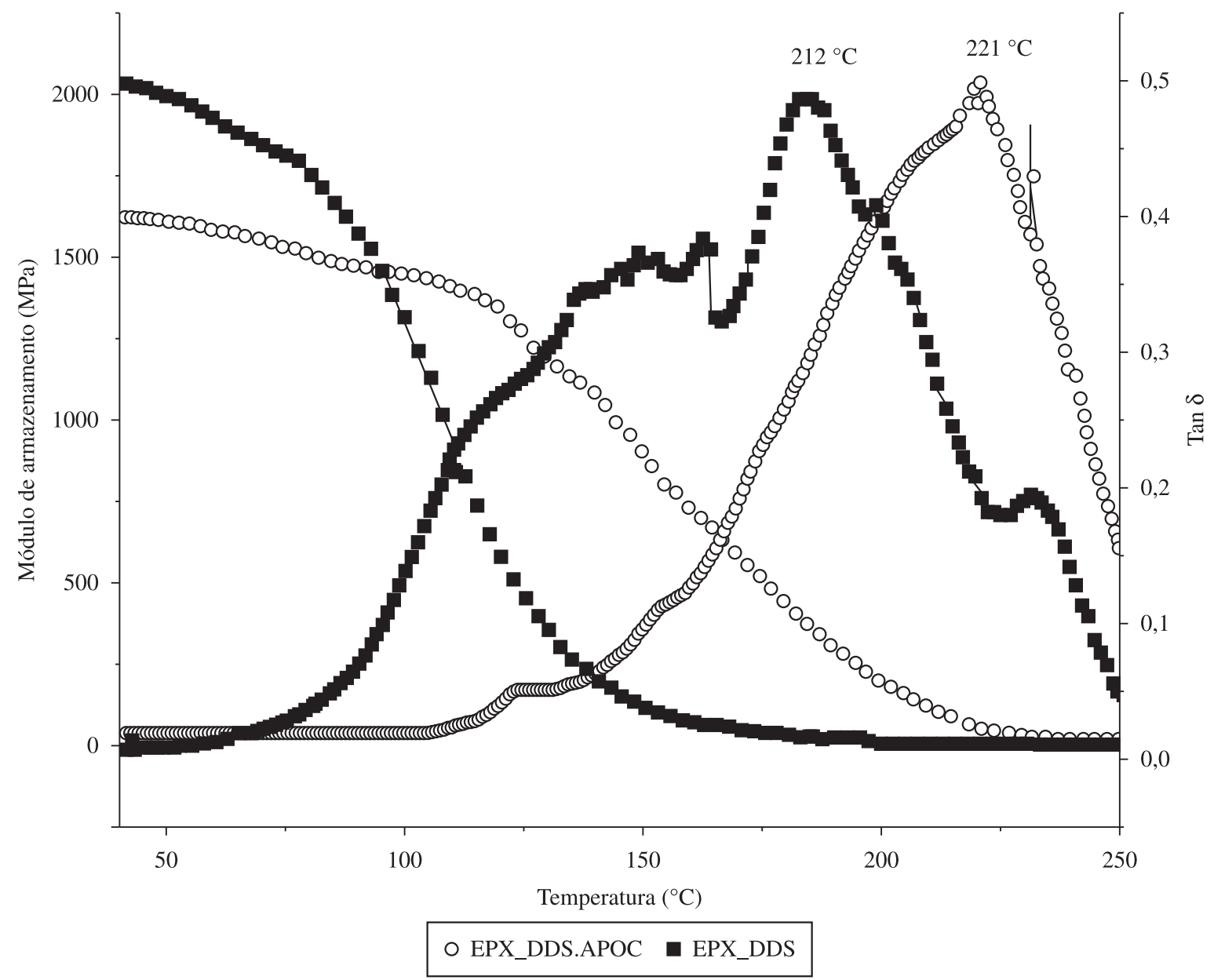

Figura 4. Curva de DMA para os sistemas epoxídicos sem argila organofílica (EPX_DDS) e com 1 pcr de argila organofílica (EPX_DDS.APOC): variação de amortecimento $(\tan \delta)$ e de módulo de armazenamento com a temperatura.

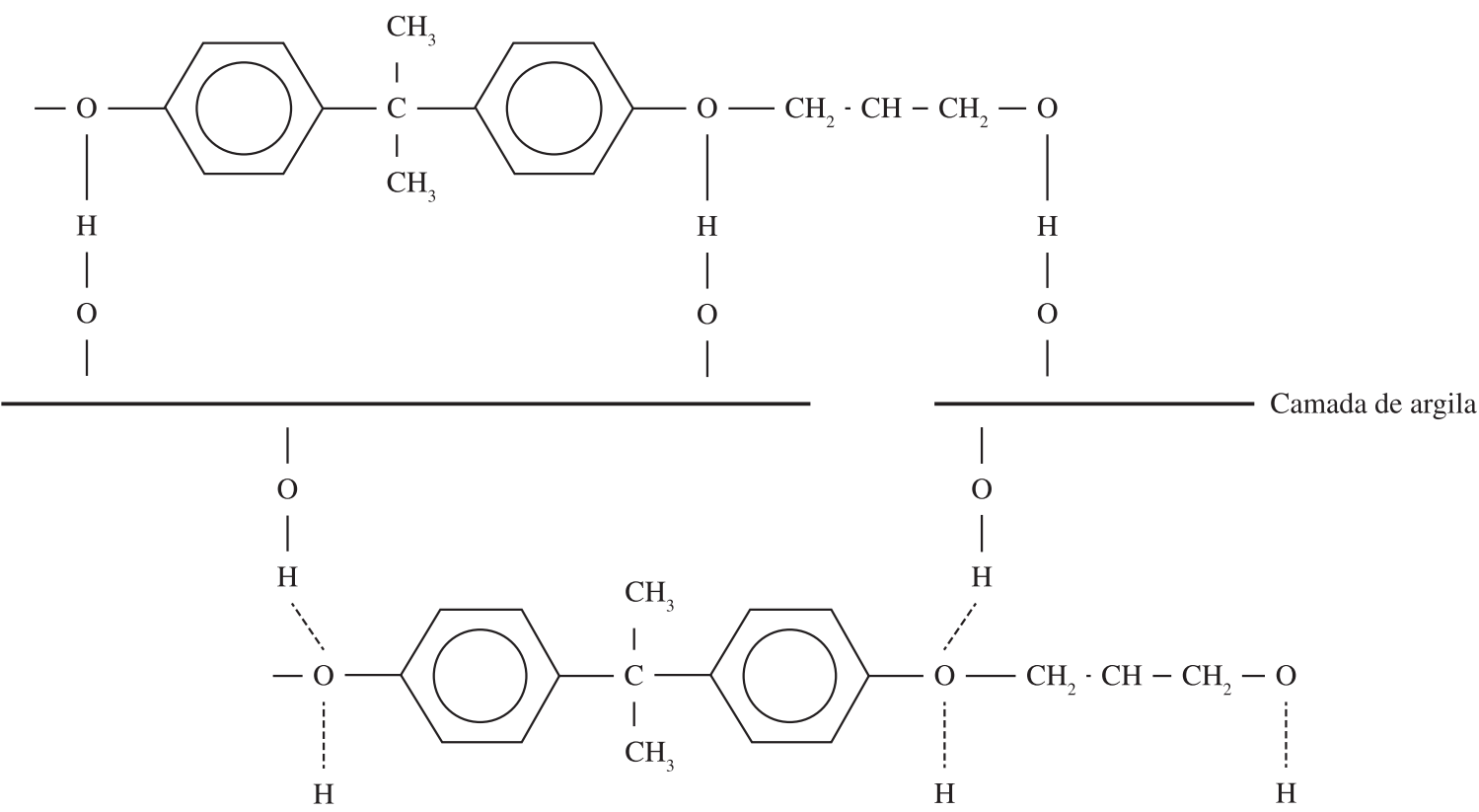

Figura 5. Interações de ligações hidrogênio entre epóxi DGEBA e camada de argila. Adaptado de Jia et al. ${ }^{[19]}$. 
é necessário que a matriz polimérica seja estável termicamente na faixa de ativação da LMF, cuja transformação de fase pode ocorrer em temperaturas situadas acima de $70{ }^{\circ} \mathrm{C}$ para LMF do sistema $\mathrm{Ni}-\mathrm{Ti}^{[6]}$.

A Figura 6 mostra o comportamento termomecânico do compósito ativo sem a argila organofílica (EPX_DDS.3,57) e dos nanocompósitos epóxi/argila organofílica contendo 1,55; 2,56; 3,57 e 4,54\% em volume de fios da LMF Ni-Ti, denominados compósitos ativos EPX_DDS.APOC 1,55, EPX_DDS.APOC 2,56, EPX_DDS. APOC 3,75 e EPX_DDS.APOC 4,54, respectivamente. Observa-se que os compósitos ativos preparados com 3,57 e 4,54\% dos fios $\mathrm{Ni}$-Ti apresentam maiores valores de módulo de armazenamento do que os preparados com 1,55 e 2,56\% de fração volumétrica. Verifica-se também que com o aumento da temperatura este módulo diminui até um valor de aproximadamente $90{ }^{\circ} \mathrm{C}$ e aumenta acima desta temperatura, quando teores superiores a $1,55 \%$ de fios $\mathrm{Ni}-\mathrm{Ti}$ são empregados. Entretanto, quando 4,54\% de fração volumétrica de fios LMF Ni-Ti foram incorporados à matriz não foram observadas diferenças significativas no comportamento do módulo de armazenamento em função da temperatura quando comparado ao compósito ativo com $3,57 \%$, ou seja, os valores de módulo apenas se mantêm estáveis na faixa de temperatura de 90 a $140{ }^{\circ} \mathrm{C}$ para o sistema contendo 4,54\% de fios da LMF (EPX_DDS.APOC 4,54). Isso ocorreu muito provavelmente devido a variação da intensidade de tensão térmica (stress térmico) entre os fios da Ni-Ti e a matriz epóxi, causada pelo aumento da fração volumétrica de $\mathrm{LMF}^{[5]}$. $\mathrm{Na}$ região de altas temperaturas, durante certo limite, essa tensão distribuída em torno dos fios diminui com o aumento do teor de fios, resultando numa diminuição da tensão interfacial entre o fio e a matriz, conforme sugerido em outros trabalhos ${ }^{[5,14,22]}$. No entanto, mesmo assim os fios LMF se sobressaem em relação a matriz, contribuindo para aumentar ligeiramente o módulo do compósito e o mantendo mais estável entre 110 e $150{ }^{\circ} \mathrm{C}$, para os sistemas contendo 3,57 e 4,54\% de fração volumétrica, quando comparado aos sistemas epoxídicos puros, sem a incorporação dos fios de LMF (Figura 4).

Um comportamento semelhante ao da Figura 6 também foi observado por $\mathrm{Ni}$ et al. ${ }^{[5]}$, que sugeriram que o teor ideal de fios LMF para que o efeito da transformação de fase seja observado durante aquecimento numa matriz polimérica a base de resina epóxi, ocorre quando sua fração volumétrica é ligeiramente superior a 3,5\%, sendo suficiente para provocar alterações em propriedades importantes como rigidez e frequência natural da estrutura composta.

Ainda na Figura 6 é possível observar o comportamento dos compósitos ativos contendo apenas a resina epóxi com 3,57\% de fios Ni-Ti sem as nanopartículas de argila, codificado como EPX_DDS 3,57. Nota-se que essa quantidade de fios de liga de Ni-Ti com EMF foi suficiente para alterar o comportamento mecânico do compósito acima de $90{ }^{\circ} \mathrm{C}$, como ocorreu no caso do compósito ativo com matriz de nanocompósito. Porém, observa-se que o módulo de armazenamento decresce acentuadamente a partir de $110^{\circ} \mathrm{C}$, não se mantendo constante como ocorre no caso da matriz EPX_DDS. APOC 3,75. Uma análise da Figura 4 indica que este resultado pode ser atribuído a maior perda de rigidez associada à matriz EPX_DDS

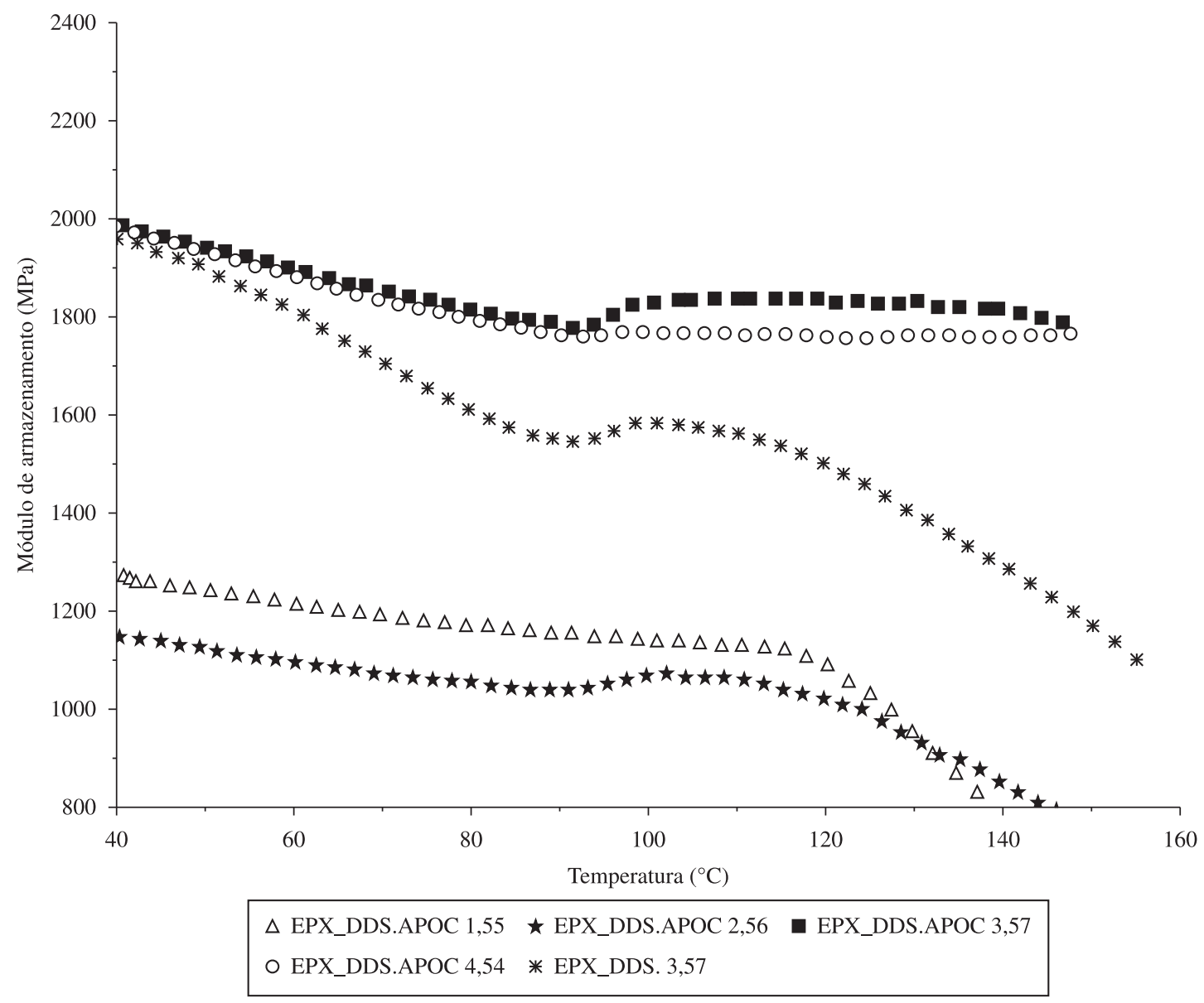

Figura 6. Variação do módulo de armazenamento com a temperatura durante o aquecimento dos compósitos ativos. 
comparativamente a matriz de nanocompósito EPX_DDS.APOC. Por outro lado, a estabilidade térmica do nanocompósito entre 100 e $140{ }^{\circ} \mathrm{C}$, sugere uma possível melhoria de interface entre os fios de $\mathrm{Ni}$-Ti e a matriz proporcionada pela introdução das nanopartículas de argila APOC, tendo em vista que a perda de rigidez é anulada nessa faixa de temperatura, contrariamente ao comportamento da matriz pura contendo os fios de Ni-Ti.

A razão para o aumento no módulo de armazenamento dos compósitos ativos, aquecidos em temperaturas superiores a $90{ }^{\circ} \mathrm{C}$, se deve a transformação dos fios da liga Ni-Ti, da fase martensita, que é menos rígida, na fase austenita de rigidez superior. Esse comportamento de aumento do módulo com a temperatura, contrário ao da matriz polimérica, pode ser claramente observado na Figura 7. Nessa figura verifica-se que o módulo de armazenamento aumenta de $28 \mathrm{GPa}$ na fase martensitica $\left(40{ }^{\circ} \mathrm{C}\right)$ para aproximadamente $50 \mathrm{GPa}$ na austenita $\left(160{ }^{\circ} \mathrm{C}\right)$. Por outro lado, a capacidade de amortecimento $(\tan \delta)$ apresenta um pico durante a transformação da martensita em austenita e depois diminui gradativamente tendendo a se estabilizar a altas temperaturas.

Essa elevação do módulo e diminuição da capacidade de amortecimento ocorre devido a eliminação gradual das placas de martensita, as quais possuem alta mobilidade levando a maleabilidade da LMF a temperaturas mais baixas e uma consequente rigidez inferior na fase martensítica se comparada à fase austenítica ${ }^{[3,6,9]}$.

A Figura 8 mostra as curvas de variação do módulo de armazenamento em porcentagem, tendo como referência o valor inicial do módulo a $40^{\circ} \mathrm{C}$. É possível observar nesta figura que, na faixa de temperatura até $140{ }^{\circ} \mathrm{C}$, a perda de módulo em porcentagem para os compósitos com 3,57 e 4,54\% de fração volumétrica de fios de LMF é de aproximadamente $12 \%$, bem inferior aos nanocompósitos sem fios de LMF e com 1,55 e 2,56\% de fração volumétrica. A porcentagem de perda de módulo para esses sistemas epoxídicos foi bastante superior, situada entre 27 e $35 \%$.

Os resultados apresentados indicam que a quantidade ideal de fios LMF de Ni-Ti que possibilita recuperar parcialmente, manter e consequentemente minimizar a perda de rigidez do compósito ativo durante seu aquecimento esta próxima a 3,5\% em volume, como sugerido também por $\mathrm{Ni}$ et al. ${ }^{[5]}$.

\section{Microestrutura dos compósitos ativos}

A microestrutura do compósito ativo, cuja matriz polimérica é constituída do nanocompósito epóxi/argila organofílica e a fase dispersa dos fios LMF Ni-Ti (compósito ativo EPX_DDS. APOC 3,57) está mostrada na Figura 9. A ausência de vazios nas micrografias sugere uma boa qualidade da interface entre o fio LMF e a matriz polimérica. Lau et al. ${ }^{[1]}$ mostraram que a alteração da rugosidade superficial e da geometria dos fios de Ni-Ti embebidos em uma matriz epóxi podem melhorar a adesão entre os fios de Ni-Ti e a matriz. Neuking et al. ${ }^{[16]}$ mostraram que as combinações adequadas de tratamento sequencial mecânico (lixamento e polimento) e físico (plasma) da superfície dos fios LMF pode resultar em boa tensão de adesão.

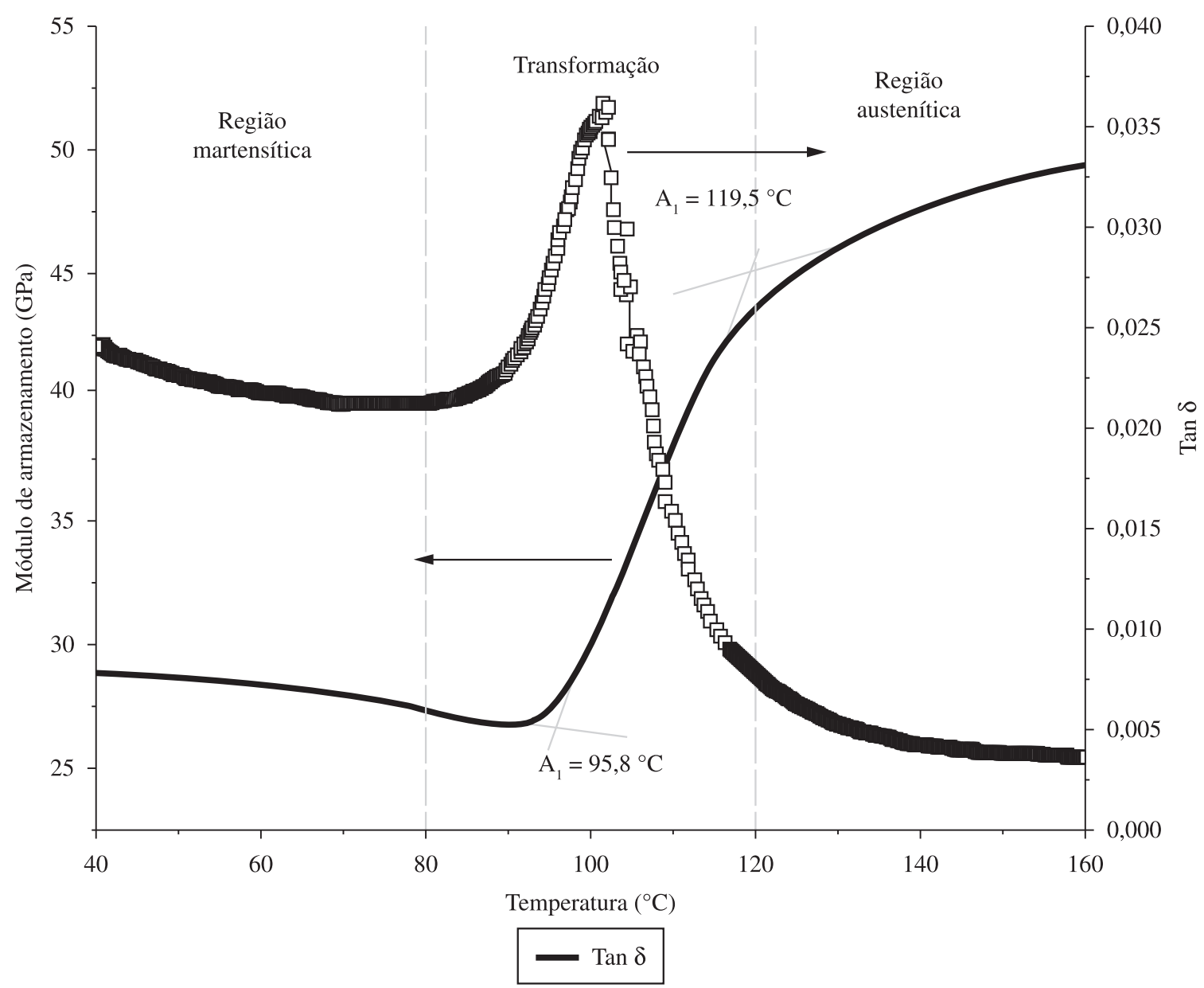

Figura 7. Curva do módulo de armazenamento e da capacidade de amortecimento ( $\tan \delta$ ) em função da temperatura para o fio de Ni-Ti tratado termicamente. 


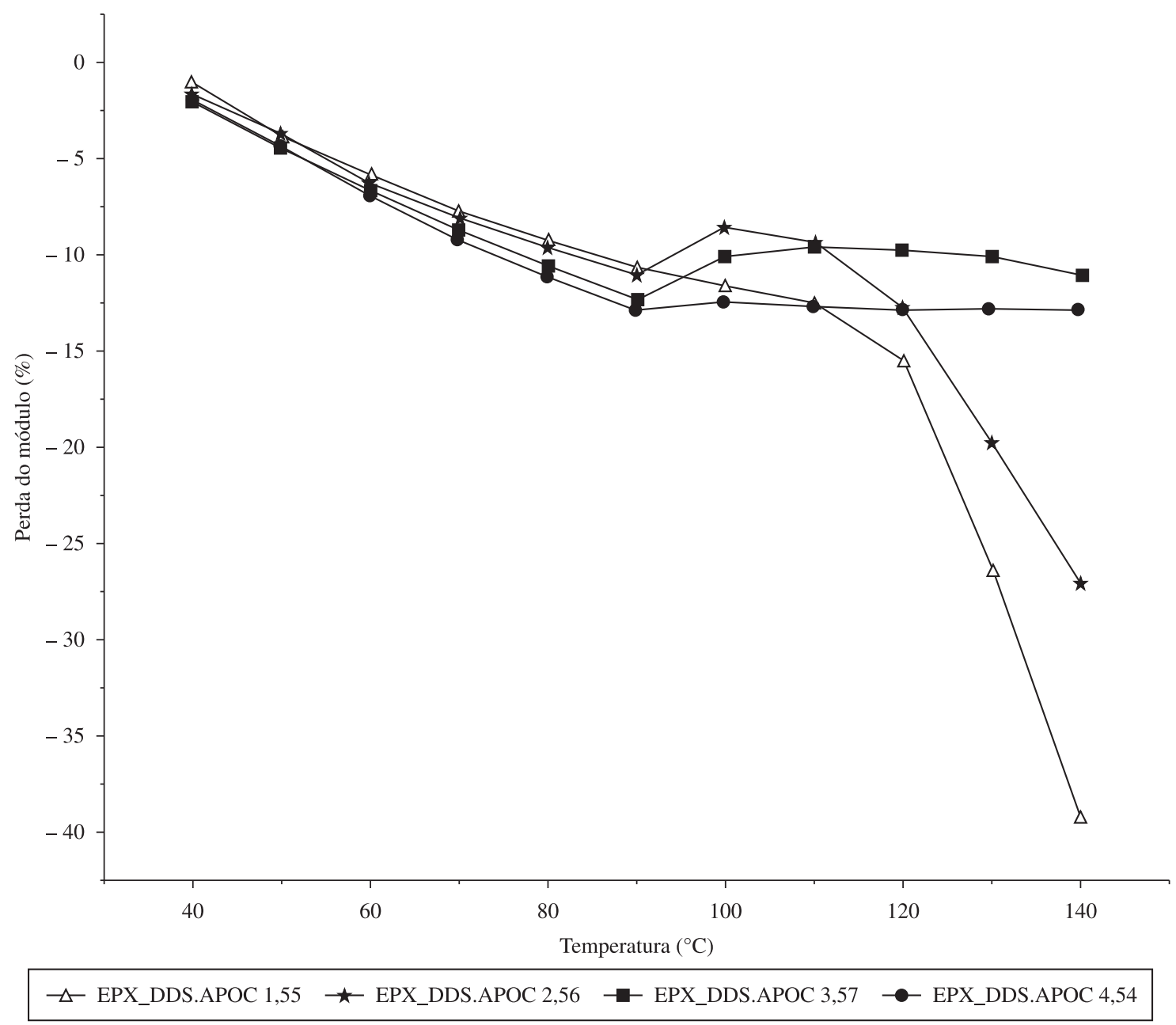

Figura 8. Variação do módulo de armazenamento em porcentagem para os compósitos ativos.

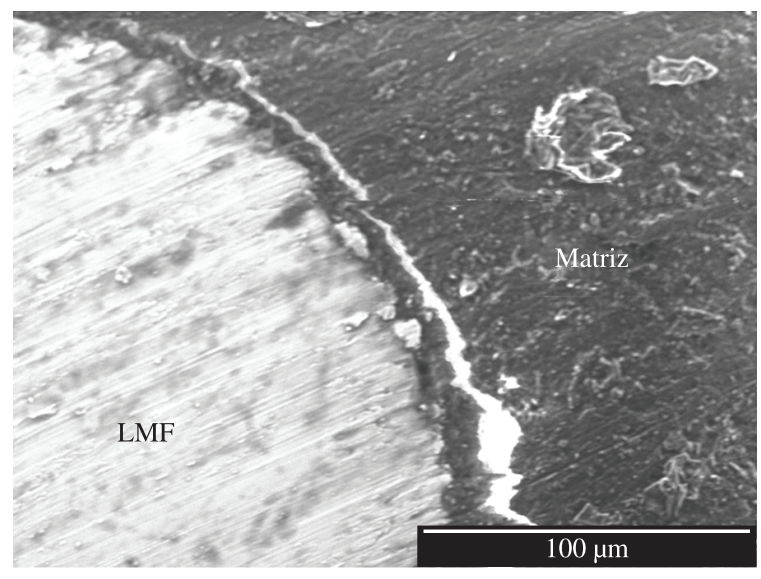

Figura 9. Fotografia da interface entre o fio de Ni-Ti e a matriz do nanocompósito epóxi/argila organofílica.

\section{Conclusões}

Os resultados obtidos neste estudo sugerem que as características de rigidez (módulo de armazenamento) dos nanocompósitos a base de resina epóxi podem ser melhoradas adicionando uma fração volumétrica de fios de LMF situada em torno de 3,5\%, originando um compósito ativo com a variação de temperatura do ambiente no qual está inserido. Quando 4,54\% de fração volumétrica de fios LMF são incorporados a matriz de nanocompósito observa-se um efeito mais reduzido da capacidade de recuperação do módulo de armazenamento quando comparado com o compósito com 3,56\%, porém é possível se manter um valor constante e controlado desta propriedade entre 100 e $150{ }^{\circ} \mathrm{C}$. Quando pequenas quantidades de fios de LMF foram incorporadas a matriz, ou seja, inferiores a 2,56\% de fração volumétrica, nenhum efeito foi observado, demonstrando que essa quantidade não é suficiente para que a transformação de fase dos fios de LMF atue positivamente na matriz epóxi durante o aquecimento do compósito formado.

\section{Agradecimentos}

Os autores agradecem a Bentonit União Nordeste-BUN pela doação da argila bentonita, a RENAMI e ao CNPq pelo apoio financeiro ao projeto casadinho UFCG-ITA (Processo 620091/2008-8) e pela concessão da bolsa de mestrado ao primeiro autor (Processo 579117/2008-1).

\section{Referências Bibliográficas}

1. Lau, K.; Zhou, L. \& Tao, X. - Comp. Struct., 58, p.39 (2002). http:// dx.doi.org/10.1016/S0263-8223(02)00042-9

2. Shimamoto, A.; Ohkawara, H. \& Nogata, F. - Eng. Fract. Mechan., 71, p.737 (2004). http://dx.doi.org/10.1016/S0013-7944(03)00052-3 
3. Michaud, V. - Scripta Mater., 50, p.249 (2004). http://dx.doi. org/10.1016/j.scriptamat.2003.09.016

4. Yang, S. M.; Roh, H.; Han, J. H. \& Lee, I. - J. Intel. Mater. Syst. Struct., 17, p.763, (2006).

5. Ni, Q. Q.;Zhang, R. X.; Natsuki,T. \& Iwamoto, M. - Compos. Struct., 79, p.501 (2007). http://dx.doi.org/10.1016/j.compstruct.2006.02.009

6. De Araújo, C. J.; Rodrigues, L. F. A.; Coutinho Neto, J. F. \& Reis, R. P. B. - Smart Mater. Struct., 17, p.18, (2008).

7. Raghavan, J.; Bartkiewicz, T.; Boyko, S.; Kupriyanov, M.; Rajapakse, N. \& Yu, B. - Composites, 41, p.214 (2010). http://dx.doi.org/10.1016/j. compositesb.2009.10.009

8. Bidaux, J. E.; Bataillard L.; Manson, J. A. \& Gotthardt, R. - J. Phys., 3, p.561, (1993).

9. Otsuka, K. \& Wayman, C. M. - "Shape Memory Materials", Cabridige University Press, New York (1998).

10. Kirkby, E. L.; Rule, J. D.; Michaud, V. J.; Sottos, N. R.; White, S. R. \& Manson, J. A. E. - Adv. Funct. Mater., 18, p.2253 (2008). http://dx.doi. org/10.1002/adfm.200701208

11. Silaex Química Ltda. - "Ficha técnica". Disponível em: <www.silaex. com.br>. Acesso em: 02 maio 2009.

12. Leite, I. F.; Soares, A. P. S.; Carvalho, L. H.; Raposo, C. M. O.; Malta, O. M. L.; Silva, S. M. L. - J. Thermal. Anal. Calorim., 100, p.563 (2010). http://dx.doi.org/10.1007/s10973-009-0265-3
13. Leal A. S. C., De Araújo, C J., Silva S. M. L. - Rev. Eletr. Mater. Proc., 5, p.34 (2010).

14. Gupta, N.; Lin, T. C. \& Shapiro, M. - Nanocomposites. Mater., p.61, (2007)

15. Wang, L.; Wang, K.; Chen, L.; Zhang ,Y. \& He, C. - Composites: Part A, 37, p.1890 (2006). http://dx.doi.org/10.1016/j. compositesa.2005.12.020

16. Neuking, K.; Abu-Zafaria, A. \& Eggler, G. - J. Mater. Sci., 11, p.481 (2008).

17. Yasmin, A.; Abot, J. L. \& Daniel, I. M. - Scrip. Mater., 49, p.81 (2003). http://dx.doi.org/10.1016/S1359-6462(03)00173-8

18. Zhang, R. X.; Ni, Q. Q.; Natsuki, T. \& Iwamoto, M. - Comp. Struc., 79, p.90 (2007). http://dx.doi.org/10.1016/j.compstruct.2005.11.032

19. Jia, Q. M.; Zheng, M.; Zhu, Y. C.; Li, J. B.; Xu, C. Z. - Polym. J., 43, p.35 (2007).

20. Lu, J. K.; Ke, T. C.; Qi, Z. N. \& Yi, X. S. - J. Polym. Sci., 39, p.115, (2001).

21. Kornmann, X.; Lindberg, H. \& Berglund, L. A. - Polymer, 42, p.4493 (2001). http://dx.doi.org/10.1016/S0032-3861(00)00801-6

22. Todd, R. I. \& Boccaccini, A. R. - Acta Mater., 47, p.3236 (1999). http://dx.doi.org/10.1016/S1359-6454(99)00177-9

Enviado: $19 / 04 / 11$

Reenviado: 05/07/11

Aceito: 05/07/11 